\title{
Developing a Brief Scale to Measure HIV Transmission Risk Among Injecting Drug Users
}

\author{
Armita Shahesmaeili, ${ }^{1,2}$ Ali Akbar Haghdoost, ${ }^{2}$ and Hamid Soori ${ }^{3,{ }^{*}}$ \\ ${ }_{1}^{1}$ Regional Knowledge Hub and WHO Collaborating Center for HIV Surveillance, Institute for Future Studies in Health, Kerman University of Medical Sciences, Kerman, IR Iran \\ 2 Research Center for Modeling in Health, Institute for Future Studies in Health, Kerman University of Medical Sciences, Kerman, IR Iran \\ ${ }^{3}$ Safety Promotion and Injury Prevention Research Center, Shahid Beheshti University of Medical Sciences, Tehran, IR Iran \\ *Corresponding author: Hamid Soori, School of Public Health, Shahid Beheshti University of Medical Sciences, Tehran, IR Iran. Tel: +98-2122431993, E-mail: hsoori@yahoo.com
}

Received 2014 December 16; Accepted 2015 February 3.

\begin{abstract}
Background: One of the main concerns of policymakers is to measure the impact of harm reduction programs and different interventions on the risk of HIV transmission among Injecting Drug Users (IDUs). Looking simultaneously at multiple factors and conditions that affect the risk of HIV transmission may provide policymakers a better insight into the mixed nature of HIV transmission.

Objectives: The present study aimed to design a simple, brief, and multi-dimensional scale for measuring HIV transmission risk among IDUs.

Patients and Methods: From October 2013 to March 2014, we conducted face-to-face interviews with 147 IDUs. Eligible participants were individuals 18 years or older who had injected drugs at least once during the last year and had not participated in similar studies within the 2 months before the interview. To design a scale for measuring HIV transmission risk, we specified 11 items, which address different dimensions of HIV risk taking behaviors/situations based on experts' opinion. We applied exploratory factor analysis (EFA) with principal component extraction to develop scales. Eigen values greater than 1 were used as a criterion for factor extraction.

Results: We extracted 7 items based on first factor, which were accounted for $21 \%$ of the variations. The final scale contained 7 items: 4 items were related to injecting practice and 3 items related to sexual behaviors. The Cronbach's $\alpha$ coefficient was 0.66 , acceptable for such a brief scale.

Conclusions: Applying a simple and brief scale that incorporates the different dimensions of HIV transmission risk may provide policymakers and harm reductionists with a better understanding of HIV transmission in this key group and may be advantageous for evaluating intervention programs.
\end{abstract}

Keywords: Needle Sharing, Intravenous Drug Abuse, Sexual Behaviour, Transmission, Iran

\section{Background}

Injection drug is one of the main modes of HIV transmission in many parts of the world, particularly in industrialized and middle-income countries, including many countries in Asia $(1,2)$. The recent global estimation in 2014 indicates that there are 12.7 million Injecting Drug Users (IDUs), and $13.1 \%$ of them are living with HIV (3). The main behaviors that increase the risk of HIV infection and other blood borne diseases such as hepatitis B and $\mathrm{C}$ among IDUs are using non-sterile needles and other injecting equipment as well as engaging in unprotected sex practices (4).

In the absence of cure for HIV infection, prevention is the best strategy for its control within the communities (5). A number of prevention strategies are implemented among IDUs around the world. Some interventions such as needle and syringe provision aim to reduce unsafe injection $(6,7)$. Other approaches aim to lower the risk of sexual transmission by distribution of condoms and education of safe sex (7-9). Recently, the interventions on personal and drug injection networks of IDUs have been greatly taken into account by many health policymakers (10-12). There is evidence that shows a higher percentage of drug injectors in the social network of IDUs are associated with increase in their risky behavior $(12,13)$.

The key outcome of interest in all strategies is the prevention of HIV and viral hepatitis (B, C) transmission among IDUs (5). For policymakers and harm reductionists who are interested in evaluating the efficacy of such programs and tracing the trends over time, applying a simple, brief, and valid measure that incorporates different dimensions of HIV transmission risks among IDUs may be more advantageous than looking at individual outcomes (14). An effective scale to measure the mixed nature of HIV transmission risks among IDUs should address all aspects of HIV transmission, including injecting drugs, sexual behaviors, and risk network characteristics

Copyright (c) 2015, Zahedan University of Medical Sciences. This is an open-access article distributed under the terms of the Creative Commons Attribution-NonCommercial 4.0 International License (http://creativecommons.org/licenses/by-nc/4.0/) which permits copy and redistribute the material just in noncommercial usages, provided the original work is properly cited. 
of individuals.

Although there are several scales that measure HIV transmission risks among populations at higher risk of HIV infection (e.g. men who have sex with men) (14-16), few scales are available for IDUs $(17,18)$ and none of them has been validated in Iran. Most of such scales have to obtain detailed and even insignificant information. The lack of risk network information within them is another limitation and indicates the demand for developing a multi-dimensional scale to capture HIV transmission by conducting a simple and brief interview that can be flexible in clinical settings, large scale surveys, and research.

\section{Objectives}

The aim of the present study was to create a brief scale applicable for policymakers, harm reductionists, and researchers for measuring HIV transmission risk among IDUs.

\section{Patients and Methods}

We collected the data related to the risk of HIV transmission among IDUs as a part of the project entitled "social network analysis of IDUs in Kerman, Iran”. From October 2013 to March 2014, three trained interviewers conducted face-to-face interviews with 147 IDUs. We used chain referral techniques to enroll a representative sample of IDUs from all affected sites, including drop-in centers, shelters, voluntary counseling, testing centers, and outreach spots. Eligible participants were individuals above 18 years old who had injected drugs at least once during the last year and had not participated in similar studies in the past 2 months. The interviews were conducted in two drop-in centers (DICs) in a very confidential setting. In some cases that the individuals were unwilling to complete the interviews at DICs, the interviewers completed the questionnaires on site.

To design a scale for measuring HIV transmission risk among IDUs, we specified 11 items, which address different dimensions of HIV risk taking behaviors/situations based on experts' opinions. The scale covered both injecting and sexual risk behaviors as well as risk network characteristics of individuals, use of stimulants, and engagement in methadone maintenance therapy (MMT).

High risk behaviors related to injection were as follows: history of needle sharing, the history of using shared cookers, cotton and rinse water; the number of needle sharing partners; average number of daily injections within the last 6 months; duration of time since first injection; and proportion of IDUs in the personal network of participants. The items related to sexual behaviors were as follows: the number of sexual partners, extent of using condoms during sexual intercourse, and whether the participants used a condom at last sex. We also asked the participants to specify if they used any types of stimulant drugs or currently engaged in MMT. Table 1 presents the items and related scores.

We applied exploratory factor analysis (EFA) with principal component extraction and varimax with Kaiser Normalization rotation to develop scales. Eigen values greater than 1 were used as a criterion for factor extraction. Items with loadings less than 0.3 were dropped. The Cronbach's $\alpha$ coefficient was calculated to estimate the internal consistency of the scale.

\section{Results}

The mean age of participants was $37 \pm 9.32$ years. Most of individuals were male (91\%), single (50.1\%), and educated up to guidance school (73.5\%) (Table 2).

We developed the final scale based on 7 items loaded on the first factor that accounted for $21 \%$ of variance. The variables and related coefficients are summarized in Table 2. The Cronbach's $\alpha$ coefficient was 0.66 , which is

acceptable for brief scales. The mean score in the overall sample was $3.002 \pm 2.33$ with a median of 2.3 (range 0 11). The maximum possible score was 15.4. The mean score in injection subscale (items 1 - 4 in Table 3 ) was $2.11 \pm 1.88$ with the median of 1.52 (range 0 - 9).The mean $( \pm S D)$ and median in sexual behavior subscale (items $5-7$ in Table 3) were $0.88( \pm 0.95)$ and 0.4 , respectively (range 0 - 3.91).

Table 1. The 11 Initial Items to Design the HIV Transmission Scale

\begin{tabular}{llll}
\hline No. Item & $\begin{array}{l}\text { Response } \\
\text { Category }\end{array}$ \\
\hline
\end{tabular}

1 The extent to which respondents used a needle that already had been used by someone else within the past 6 months

\begin{tabular}{|c|c|c|c|}
\hline & & Never & 0 \\
\hline & & Sometimes & 1 \\
\hline & & Usually & 2 \\
\hline & & Always & 3 \\
\hline \multirow[t]{3}{*}{2} & $\begin{array}{l}\text { The extent to which respondents used cookers, rinse water, or cotton after someone else had } \\
\text { already used them within the past } 6 \text { months }\end{array}$ & & \\
\hline & & Never & 0 \\
\hline & & Sometimes & 1 \\
\hline
\end{tabular}


Shahesmaeili A et al.

The number of people that had used a syringe before respondents used it within the past 6
months

(1)

4 The proportion of IDUs in personal network of respondents

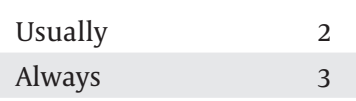

\begin{tabular}{ll} 
None & 0 \\
1 person & 1 \\
2 persons & 2 \\
\hline 3 persons & 3 \\
4 persons & 4 \\
5 persons & 5 \\
6 persons or more & 6
\end{tabular}

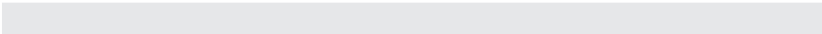

$\begin{array}{ll}0 & 0 \\ 1 \%-24.9 \% & 1 \\ 25 \%-49.9 \% & 2 \\ 50 \%-74.9 \% & 3 \\ \geq 75 \% & 4\end{array}$

5 The duration from the first injection

$\begin{array}{ll}<5 y & 1 \\ 5-10 y & 2 \\ >10 y & 3\end{array}$

6 The average number of daily injections

\begin{tabular}{ll} 
Once a day or less & 1 \\
\hline Twice a day & 2 \\
\hline Three times a day & 3 \\
\hline Four time a day & 4 \\
$\begin{array}{l}\text { Five times a day or } \\
\text { more }\end{array}$ & 5
\end{tabular}

7 The number of sexual partners within the past 6 months

\begin{tabular}{|c|c|c|c|}
\hline & & None & 0 \\
\hline & & 1 person & 1 \\
\hline & & 2 persons & 2 \\
\hline & & 3 persons & 3 \\
\hline & & 4 persons & 4 \\
\hline & & 5 persons & 5 \\
\hline & & 6 persons or more & 6 \\
\hline \multirow[t]{5}{*}{8} & The extent of using condoms during sexual intercourse within the past 6 months & & \\
\hline & & Never & 3 \\
\hline & & Sometimes & 2 \\
\hline & & Usually & 1 \\
\hline & & Always & 0 \\
\hline \multirow[t]{3}{*}{9} & The use of condoms during the last sexual intercourse & & \\
\hline & & Yes & 0 \\
\hline & & No & 1 \\
\hline \multirow[t]{3}{*}{10} & If the respondent is currently under MMT & & \\
\hline & & Yes & 0 \\
\hline & & No & 1 \\
\hline \multirow[t]{3}{*}{11} & If the respondent used any stimulant drug within the past 6 months & & \\
\hline & & No & 0 \\
\hline & & Yes & 1 \\
\hline
\end{tabular}


Shahesmaeili A et al.

\begin{tabular}{lc}
\hline Table 2. The Demographic Characteristics of 147 Injecting Drug Users & \\
\hline Characteristic & Value \\
\hline Age, $\mathbf{y}$ & $37 \pm 9.32$ \\
\hline Mean \pm SD & 20 \\
\hline Minimum & 36 \\
\hline Maximum & \\
\hline Education ${ }^{\text {a }}$ & $52(35.3)$ \\
\hline Illiterate or Primary school & $56(38.1)$ \\
\hline Guidance school & $39(26.5)$ \\
\hline High school and above & \\
\hline Marital status & \\
\hline Single & $76(51.7)$ \\
\hline Married & $37(25.2)$ \\
\hline Divorced & $30(20.4)$ \\
\hline Widowed & $4(2.7)$ \\
\hline Gender & \\
\hline Male & $134(91.2)$ \\
\hline Female & $13(8.8)$ \\
\hline
\end{tabular}

${ }^{\mathrm{a}}$ Values are presented as number (\%).

Table 3. Factor Loadings of Final 7 HIV Transmission Risk Items Among 147 Injecting Drug Users

\begin{tabular}{lll}
\hline No & Item & Factor Loading \\
\hline $\mathbf{1}$ & $\begin{array}{l}\text { The extent to which respondents used a needle that already had been used by someone else within the } \\
\text { past } 6 \text { months }\end{array}$ \\
$\mathbf{2}$ & $\begin{array}{l}\text { The number of people that had used a syringe before respondents used it within the past } 6 \text { months } \\
\mathbf{3}\end{array}$ & $\begin{array}{l}\text { The extent to which respondents used cookers, rinse water, or cotton after someone else had already used } \\
\text { them within the past } 6 \text { months }\end{array}$ \\
$\mathbf{4}$ & The proportion of IDUs in the personal network of respondents \\
$\mathbf{5}$ & The extent of using condoms during the sexual intercourses within the past 6 months \\
$\mathbf{6}$ & The number of sexual partners within the past 6 months \\
$\mathbf{7}$ & The use of condoms during the last sexual intercourse & 0.62 \\
\hline
\end{tabular}

\section{Discussion}

The results of the present study indicate that employing a 7-item scale to measure the HIV transmission risk among IDUs may be useful for evaluation of intervention programs in this key group. In many studies, the focus of risk analysis is on discrete behaviors to identify trends in behaviors or to study the determinants of high risk behaviors in this population $(19,20)$. For a better understanding of the current status of HIV transmission risks among IDUs, looking simultaneously at multiple factors and conditions may provide better insight for policymakers and researchers into the mixed nature of HIV transmission risks and assist with identifying IDUs with higher risk of HIV acquisition or transmission based on their behaviors. Furthermore, measuring the impact of interventions on multiple discrete outcomes may increase the chance of type I errors by introducing the problem of multiplicity into the analysis (21).

To prepare this scale; we used principal component analysis, a multivariate technique which simplifies a set of items to their linear combination in a way that they successively have a maximum variance for the data. The measure of internal consistency, the Cronbach $\alpha$, was satisfactory, which indicates that summation of different items to construct a global scale for measuring HIV transmission risks is proper. This approach may be more statistically powerful and informative in etiologic research as well as program evaluation efforts.

Regarding high risk behaviors related to injection practice, the highest weight pertained to the needle sharing followed by the number of injection partners and sharing of injection equipment. These findings are supported by the literature that suggests the higher 
likelihood of HIV transmission among those who share needles with multiple partners than those who only share injection equipment such as cookers or rinse water (22). In addition, the use of a condom during sexual intercourse is of much more significance than the number of sexual partners. Another item that was extracted in the final scale was proportion of IDUs in the personal network of participants. This item has been ignored in available scales while in many situations, the higher proportion of IDUs in personal networks of individuals has been associated with a higher rate of risky behaviors $(12,13)$. In addition, out of 11 items that we entered in the initial scale, 4 were dropped from the final model. These items were duration of injection, average number of daily injections, engagement in MMT program, and use of stimulant drugs within the last 6 months. As these items indirectly affect the risk of HIV transmission among IDUs, it is uninformative to retain them in this scale.

We asked about the high risk behaviors of IDUs during the last 6 months to take into account the turnover of their relations that usually exist among IDUs. In addition, we supposed that some questions such as the number of anal intercourse acts during the last month (that was considered by Darke and colleagues in a similar scale) does not necessarily affect the risk of HIV transmission (17). Instead, the safety of sexual acts (e.g. use of condoms) is the main determinant of HIV transmission during sexual relationship. Therefore, such items dropped from our suggested scale.

In conclusion, applying a 7-item scale can help harm reductionists and clinical practitioners to simply measure the current status of HIV transmission risks among IDUs in a short period of time (3 - 5 minutes). It also provides an opportunity for policymakers to evaluate the impact of intervention programs by measuring the changes in HIV transmission risk by employing a comprehensive scale that captures different factors related to virus transmission. Undoubtedly, an effective rapport between interviewers and participants increase the validity of such self-reported data. Nevertheless, the cross-sectional nature of the data has limited our ability to assess the usefulness of scales in prediction of HIV seroconversion among IDUs. So, prospective cohort studies are needed to assess the predictive validity of scales.

\section{Acknowledgments}

All authors kindly acknowledge Dr Mojtaba Shojaei for his useful suggestions on designing the questionnaire. We also like to thank Mr Maoud Izadpanah and Mrs Baghizadeh for conducting the interviews. We also acknowledge Dr Mohammad Reza Baneshi and Mr Farzan Madadi for their counseling on statistical analysis. This is a part of a PhD thesis by Dr. Shahesmaeili taken place at the department of epidemiology, school of public health, Shahid Beheshti University of Medical Sciences, Tehran, Iran.

\section{Footnotes}

Authors' Contribution:Armita Shahesmaeili developed the original idea and the protocol, abstracted and analyzed data, and wrote the manuscript. Ali Akbar Haghdoost and Hamid Soori contributed to the design of the project, and manuscript preparation.

Funding/support:This study was partially supported by Shahid Beheshti University of Medical Sciences.

\section{References}

1. Harm Reduction International. The global state of harm reduction 2012: towards an integrated response. 2012. Available from: http:| www.ihra.net/files/2012/07/24/GlobalState2012_Web.pdf.

2. World Health Organization . In: Surveillance of Populations at High Risk for HIV Transmission. Regional Office for South-East Asia , editor. Geneva: 2007. Available from: http://www.cpc.unc. edu/measure/training/materials/m-e-of-hiv-aids-programs-inindia-english/session-6-gender-and-surveys-surveillance/surveyssurveillance/Surveillance\%20of\%20Populations\%20at\%20High\%20 Risk\%20for\%20HIV\%20Transmission.pdf/view.

3. UNODC. World drug report 2014. Vienna: United Nations Office on Drugs and Crime; 2014. Available from: http://www.unodc.org/ wdr2014/.

4. Mumtaz GR, Weiss HA, Thomas SL, Riome S, Setayesh H, Riedner $\mathrm{G}$, et al. HIV among people who inject drugs in the Middle East and North Africa: systematic review and data synthesis. PLoS Med. 2014;11(6):e1001663. doi: 10.1371/journal.pmed.1001663. [PubMed: 24937136]

5. Degenhardt L, Mathers B, Vickerman P, Rhodes T, Latkin C Hickman M. Prevention of HIV infection for people who inject drugs: why individual, structural, and combination approaches are needed. Lancet. 2010;376(9737):285-301. doi: 10.1016/S01406736(10)60742-8. [PubMed: 20650522]

6. Palmateer N, Kimber J, Hickman M, Hutchinson S, Rhodes T, Goldberg D. Evidence for the effectiveness of sterile injecting equipment provision in preventing hepatitis $\mathrm{C}$ and human immunodeficiency virus transmission among injecting drug users: a review of reviews. Addiction. 2010;105(5):844-59. doi: 10.1111/j.1360-0443.2009.02888.x. [PubMed: 20219055]

7. Golden RE, Collins C, Cunningham S, Newman EN, Card JJ. Overview of Structural Interventions to Decrease Injection Drug-Use Risk. Best Evidence Structural Interventions for HIV Prevention. Germany: Springer; 2013. pp. 41-121.

8. Beyrer C, Malinowska-Sempruch K, Kamarulzaman A, Kazatchkine M, Sidibe M, Strathdee SA. Time to act: a call for comprehensive responses to HIV in people who use drugs. Lancet. 2010;376(9740):551-63. doi: 10.1016/S0140-6736(10)60928-2. [PubMed: 20650515]

9. Mathers BM, Degenhardt L, Ali H, Wiessing L, Hickman M, Mattick RP, et al. HIV prevention, treatment, and care services for people who inject drugs: a systematic review of global, regional, and national coverage. Lancet. 2010;375(9719):1014-28. doi: 10.1016/S0140-6736(10)60232-2. [PubMed: 20189638]

10. Valente TW. Network interventions. Science. 2012;337(6090):4953. doi: 10.1126/science.1217330. [PubMed: 22767921]

11. Latkin CA. A personal network approach to AIDS prevention: an experimental peer group intervention for street-injecting drug users: the SAFE study. NIDA Res Monogr. 1995;151:181-95. [PubMed: 8742766]

12. Strathdee SA, Hallett TB, Bobrova N, Rhodes T, Booth R, Abdool R, et al. HIV and risk environment for injecting drug users: the past, present, and future. Lancet. 2010;376(9737):268-84. doi: 10.1016/ S0140-6736(10)60743-X. [PubMed: 20650523]

13. Suh T, Mandell W, Latkin C, Kim J. Social network characteristics and injecting HIV-risk behaviors among street injection drug users. Drug Alcohol Depend. 1997;47(2):137-43. [PubMed: 9298335]

14. Fendrich M, Smith EJ, Pollack LM, Mackesy-Amiti ME. Measuring sexual risk for HIV: a Rasch scaling approach. Arch Sex Behav. 2009;38(6):922-35. doi: 10.1007/s10508-008-9385-2. [PubMed: 
18551361]

15. Reed SJ. A Study of the Validity of a Modified Ordinal Scale of HIV Transmission Risk Among Seropositive Men who Have Sex with Men. Ohio: The Ohio State University; 2012.

16. Jemmott JB, Jemmott LS, Fong GT. Reductions in HIV risk-associated sexual behaviors among black male adolescents: effects of an AIDS prevention intervention. Am J Public Health. 1992;82(3):372-7. [PubMed: 1536352]

17. Darke S, Hall W, Heather N, Ward J, Wodak A. The reliability and validity of a scale to measure HIV risk-taking behaviour among intravenous drug users. Aids. 1991;5(2):181-6. doi: 10.1097/000 02030-199102000-00008. [PubMed: 2031690]

18. Dowling-Guyer S, Johnson ME, Fisher DG, Needle R, Watters J, An dersen M, et al. Reliability of drug users' self-reported HIV risk behaviors and validity of self-reported recent drug use. Assessment. 1994;1(4):383-92.

19. Dutta A, Wirtz AL, Baral S, Beyrer C, Cleghorn FR. Key harm reduction interventions and their impact on the reduction of risky behavior and HIV incidence among people who inject drugs in low-income and middle-income countries. Curr Opin HIV AIDS. 2012;7(4):362-8. doi: 10.1097/COH.0b013e328354aob5. [PubMed: 22647588]

20. Fatseas M, Denis C, Serre F, Dubernet J, Daulouede JP, Auriacombe M. Change in HIV-HCV risk-taking behavior and seroprevalence among opiate users seeking treatment over an 11-year period and harm reduction policy. AIDS Behav. 2012;16(7):2082-90. doi: 10.1007/s10461-011-0054-4. [PubMed: 21983799]

21. Benjamini Y. Simultaneous and selective inference: Current successes and future challenges. Biom J. 2010;52(6):708-21. doi: 10.1002/bimj.200900299. [PubMed: 21154895]

22. UNAIDS. Guidelines on modeling the expected short-term distribution of new hiv infections by modes of transmission. New York: Joint United Nations Programme on HIV/AIDS; 2012. Available from: http://www.unaids.org/sites/default/files/en/media/ unaids/contentassets/documents/document/2012/guidelines/ JC2427_ModelingNewHIVInfectionsbyModesofTransmission_ en.pdf. 